\title{
MOTORWAY OPERATION AND MAINTENANCE: CASE STUDY AZERBAIJAN
}

\author{
Igor Jokanović, Maurizio Rotondo, Dragan Mihajlović
}

Preliminary communication

Development of a strategy for a new approach to the management of the most important road network of Azerbaijan, the main road network, required to carefully examine all the aspects concerning delivery of operation and maintenance services and functions. Guiding principles and objectives for the future management of the Azeri main road network were defined, and according to them a set of possible options has been proposed. The options were compared on the basis of a SWOT analysis in order to shortlist those that may best fit the current and the near future Azeri scenario.

Keywords: asset management; management unit; operation and maintenance; strategy

Eksploatacija i održavanje autoputa: studija slučaja Azerbejdžan

Prethodno priopćenje

Razvoj strategije za primjenu novog pristupa upravljanju najvažnije cestovne mreže Azerbejdžana, glavne cestovne mreže, je zahtijevao da se pažljivo ispitaju svi aspekti u svezi s osiguravanjem usluga i funkcija eksploatacije i održavanja. Definirani su vodeći principi i ciljevi za buduće upravljanje azerbejdžanskom glavnom cestovnom mrežom, a prema njima i predložen niz mogućih opcija. Opcije su uspoređene na temelju SWOT analize kako bi bile odabrane one koje najbolje odgovaraju azerbejdžanskom scenariju u sadašnjosti i bliskoj budućnosti.

Ključne riječi: eksploatacija i održavanje; jedinica za upravljanje; strategija; upravljanje kapitalom

\section{Introduction}

Practices in road networks management vary even dramatically depending on the approached country. Differences may depend on a number of factors, such as social, historical, financial situation, and can also depend on some physical characteristics of the network. Ownership (or control, that may be assigned to specific bodies although the "ownership" remains of the state/region or other local authorities) can be different, and it can influence technical as well as legal and financial practice. The presence of organized users' entities (automobile clubs, consumers associations, etc.) is sometimes a major driver for the improvement of the management.

It is then quite a challenge to frame the various approaches and practices so as to derive useful examples and conclusions, since each and every choice has precise roots in some specific characteristics of the examined countries and regions.

National and international road networks differ from other networks in a number of ways that impact their need for maintenance, how maintenance is undertaken and the effects of lack of maintenance. Primary networks in developed nations do have such a level of importance and of specific needs that their management (including Operation and Maintenance (O\&M)) asks for special and high level capabilities and knowledge. The common practice is the one of "linear management" of primary roads, as opposed to "area management" that may find application on lower level road networks (secondary and local roads). The management should therefore not be merged with the one of lower level networks, and may include an increasing number of traffic management tasks well beyond the simple construction and repair of the road.

This paper examines the current O\&M practice for Azerbaijan main road network and presents options for the future management and delivery of O\&M services and functions.

\section{Asset management: a comprehensive concept}

A natural evolution that is also taking place in developed countries is the shift towards the concept of Road Asset Management (RAM), i.e. asset management applied to road (primary roads in general) networks. Asset management is defined by the World Road Association (PIARC) [1, 2], as: "A systematic process of maintaining, upgrading and operating assets, combining engineering principles with sound business practice and economic rationale, and providing tools to facilitate a more organized and flexible approach to making the decisions necessary to achieve the public's expectations".

In the PIARC description, RAM is basically the institutionalizing of a business-like approach (culture) to managing road infrastructure. This implies: (i) looking at projects and programs as investments for specific customers, (ii) monitoring asset performance and value in order to trade-off project alternatives and investments, and (iii) developing sound and competitive short and long-term investment strategies.

This approach fully acknowledges the fact that changes are occurring in many countries worldwide, where road administrations are shifting from governmental organizations to agency status and, in some very advanced model, to private enterprises. In this framework governmental direct input tends to decrease in favor of rule setting, while private risks taking increases and the road user is increasingly regarded as "customer" $[1,2]$.

The results of the road network management activities are regarded as a service or product to be supplied to a client. In the conventional road administration model, the road network quality levels are typically the result of old technical or functional 
requirements and standards and, sometimes, aiming at obsolete functions.

The agency model is instead characterized by a contractor-client relationship, in which the roles of the client and the contractor are distinct and separate: the client (the government or the governmental entity) passes a contract with the agency (the contractor) that can be based on Service Level Agreement (SLA). The client has obviously to clearly formulate his requirements and his objectives. Eventually the SLA based contract will deal not so much with products as with the level of the services that the road network manager has to ensure.

Asset management asks also for a thorough knowledge based approach, in which the client is capable to analyze in detail its infrastructures and their characteristics, so to properly fix the objectives. Fig. 1 summarizes the main components of an Asset Management System (AMS). Preventive maintenance concepts are obviously part of asset management and play an important role in the SLAs components.

\begin{tabular}{|c|c|c|c|}
\hline & & & \\
\hline $\begin{array}{l}\text { Performance } \\
\text { measures }\end{array}$ & $\begin{array}{l}\text { Asset value, } \\
\text { condition and } \\
\text { performance } \\
\text { assessment }\end{array}$ & $\begin{array}{c}\text { Alternative } \\
\text { generation and } \\
\text { evaluation }\end{array}$ & $\begin{array}{l}\text { Trade-off analyses } \\
\text { and investment } \\
\text { strategies }\end{array}$ \\
\hline
\end{tabular}

Figure 1 Asset management main components [1]

Components of the asset management comprehensive approach to the road management and its optimization can be applied in phases, merged and split according to the conditions and to the system maturity. It can be scaled back to components that are needed at a certain time, but it allows for a well-organized and optimized approach.

\section{The big shift: from maintenance to operation and maintenance}

Duties of a road O\&M operator are evolving, and may include tasks beyond the basic asphalt/concrete/steel approach. Even though this evolution may appear somehow premature for the Azeri scenario it is important to explore it because its consideration may affect medium and long-term strategies for the O\&M service.

In clarifying the means and roles that O\&M encompasses in developed countries it is useful to explore the concept of the "Big Shift", as the Western European Road Directors group defined it a few years ago [3]. The Big Shift is considered as composed of two distinct shifts, such as: (i) the shift from road construction to road network optimization, and (ii) the shift from road network optimization to road network user support. This concept was later on embedded in a PIARC's comprehensive report on network operation [4].

The two steps can also ideally be of guidance for medium- and long-term development for a road manager in a transformational phase.

The first step, from pure road construction to road optimization will generally see better traffic management, ranging from re-active maintenance and traffic influencing at point level (simple regulation where problems or traffic conflicts occur) to pro-active traffic influencing at network level (traffic preventive regulation, for instance of traffic streams to economic centers during rush hours). In the shift from road network optimization to road network user support it is important to distinguish between the "external" view, focused on the services needed by road users, and the "internal" view, focused on the operations needed to deliver the services.

Such an approach asks for an in-depth analysis of the organization and of its medium and long-term objectives. Coupled with the "asset management" concept, the Big Shift concept further clarifies the range of the challenges a primary network operator may have to face. The role of a primary road network manager may ask for capability and knowledge in a broad range of subjects and of activities, not yet dealt with along the Azeri primary network. It is advisable to determine a sustainable stepwise approach of implementation.

\section{Issues for the Azeri main road network management}

The total length of road network in the Azerbaijan Republic is $18977 \mathrm{~km}$, including main territory, disputed area of Nagorno-Karabakh and autonomous Nakhchivan region. The most recent inventory survey [5] shows that AzerYolServis ASC (AYS) manages $1596 \mathrm{~km}$ of main roads, $1724 \mathrm{~km}$ of regional roads and $9799 \mathrm{~km}$ of local roads, for a total network of $13119 \mathrm{~km}$. Major road development is underway in Azerbaijan at present, with network expansion needed to help capitalize on the country's strong extraction industry. Most of the main roads are already upgraded to motorway standards with four or more traffic lanes.

From the comparison of the capacity assessment findings $[6,7]$ and the analysis of the international experience $[7,8]$ relevant differences result between the Azeri O\&M practices and those applied internationally.

The differences may be summarized in the following main points:

(i) Area management vs. linear management: The current Azeri road management is based on area units dealing with the most of the roads assets within their jurisdiction. The international practice is the creation of specialized entities (public or private, depending on countries, evolution, etc.) for the "linear" management of specific roads/motorways trunks;

(ii) The $\mathrm{M}$ part of the O\&M in Azerbaijan is currently dealt with by means of a centralized prescriptive approach, related to the infrastructure as such rather than to the function or service they have to deliver. The international evolution is instead in the direction of turning the approach upside down, by linking directly the actions to be taken to the functions/services to be delivered, and deriving from them the single components to be deployed, that can be based on technical standards;

(iii) The relationship in defining the needed resources and in assessing effectiveness between the managing authority and the implementing units is prescriptive and based on an "administration-to-administration" relationship. This practice was common also in the now more developed nations in the past decades, but it has been or it is being taken over by a different, more business-like approach, in which the managing authority dictates functions and evaluates the results, while the implementing entities have a relatively high 
degree of freedom in choosing how to satisfy the prescribed functions. Private entities may also deliver the service in a competitive market environment, under the control of the managing authority;

(iv) The $\mathrm{O}$ part of the O\&M in Azerbaijan approach is at present dealt with by many entities, without a direct involvement of the road managing authority. The current international practice is to assign to the road managing authority a pivotal role among all the actors in charge of operation, in order to ensure consistency, timeliness and the availability of a proper chain of command in everything that has to do with primary roads management. Additional services based on ITS (Intelligent Transportation System) may also rapidly appear and may need to be properly accommodated in the road management framework.

There is a significant gap between the international consolidated practice in primary road networks O\&M and the current Azeri practice; examples are available for overall organization, for contracting practices, for technical means and methods. There is ample room for evolution in the primary network O\&M practice and the international historical experience tells that a comprehensive approach in framing all the components of the O\&M also in a long-term perspective can be beneficial for planning purposes.

\section{Principles and objectives for operation and maintenance of the Azeri main road network}

Azerbaijan is a country in rapid development and its basic situation is similar to the past situation of some of the developed nations that successfully engaged in the evolutionary process. The phasing of the process will undoubtedly be a challenge, but its steps may be at least listed and agreed upon.

\subsection{Principles}

The reflection on the principles has to start from the role the main road network ( $\mathrm{M}$ network) has to play in the development of Azerbaijan:

(i) it is the backbone of the national transportation system, in terms of internal communications as well in terms of international corridors;

(ii) it has to permit safe, reliable and timely journeys, as a condition for the road transport to underpin the spatial, economic and social development of the nation;

(iii) it may remain the sole communication and transportation means in case of emergencies and calamities.

From this, definition clearly stands out that the O\&M function cannot stay "re-active only" for long, since the satisfaction of the needs described above requires preparedness, planning, capacity to define, adapt and deploy suitable strategies.

It is then possible to define the main guiding principles that will be applied in the following: (i) the O\&M functions and services along the M network have to be highly specialized and fully separated from the maintenance functions and services of the rest of the road network; the M network has to be dealt with as composed of linear corridors and not as a part of a galaxy of non-hierarchized roads;

(ii) experience is present, although fragmented and still insufficient, in the existing Road Maintenance Units (RMU); it might be capitalized and adapted to the new "linear" concept;

(iii) a continuous learning process will be needed since any strategy will need adaptation in time, and the entities in charge of the $M$ network management have to be capable of applying state of the art solutions;

(iv) the application of the RAM concept may enhance the efficacy of the intervention, helping setting also longterm objectives consistent with the most advanced international practice;

(v) the O\&M practices along the $\mathrm{M}$ network should become state of the art for Azerbaijan and serve as leading example also for the management of the lesser networks;

(vi) separation of roles and responsibilities between the "controller", i.e. the authority in charge of monitoring and guiding the O\&M enhancement, and the executors, i.e. the entities that will have to actually apply the required functions and services; the relationship should become the one of clientcustomer and, although in the medium long-term, allow for some market competition and the entry of the private sector in the provision of the intended services;

(vii) in order to fully respond to the future necessities the analysis should also include modern operation concepts from the very beginning, with elements of traffic management issues, so as to be ready to implement the proper procedures on current issues and on future issues when the needs will arise.

\subsection{Objectives}

The following objectives were derived according to the results of the international benchmarking and to the above principles.

1. Start the design of a RAM approach for the $M$ network

1.1 Make available a knowledge based tool (e.g. dynamic database on infrastructure and traffic) on which to base a preventive maintenance strategy

1.2 Define road components management systems

1.3 Define time horizons for the RAM development;

2. Fully set up the Motorway Unit (MU) and assign specific tasks (ongoing);

3. Apply the "linear" O\&M concept to the M network;

4. Create specific entities for the $M$ network only, in charge indicatively each of similar length of the network and if possible of similar typology (e.g. traffic levels and composition, mountain/plain, etc.);

5. Assess the needs of each entity according to the characteristics of the network assigned to it;

6. Design a continuous education process of all the involved personnel; 
7. Define the components of the operation and plan for their gradual introduction in practice.

\section{Options for operation and maintenance on the Azeri main road network}

The comparison with the international situation and practice $[7,8]$, together with the analysis on the current capacity in O\&M [6,7] suggested examining possible changes in the current organization.

Change implies choices, which have to be carefully balanced since they may have many facets and many consequences; choices may also depend on the maturity of the system and they may therefore evolve in time.

For this reason also options that may appear extreme or hardly feasible right now were examined, because they may become a natural evolution in time of options that will be immediately chosen.

The following options were analyzed [9]:

A. "Do-nothing" scenario, i.e. keep the current organization and rules, under the control of the newly formed MU: This option includes the existing set up of the MU that would act as a central coordinator/manager of the existing RMUs for the O\&M along the M network only. The RMUs may be refurbished and/or enhanced in terms of personnel, materials and equipment, and they would go on servicing the entire road network;

B. "Linear" O\&M approach, specialized to the $\mathrm{M}$ network, creation of a limited number of Motorway Maintenance Units (MMUs): In this option the M network O\&M is assigned to MMUs that would deal exclusively with this network. The MMUs should be in charge of trunks for a certain number of $\mathrm{km}$ (according to some international practice the range may go from $100 \mathrm{~km}$ to $300 \mathrm{~km}$ ). The MMUs would have their own personnel and equipment and they would work on the basis of the rules and methods applied now;

C. "Linear" O\&M approach, specialized to the $M$ network, creation of a limited number of MMUs, design of an AMS: This option is basically similar to the option B, integrated by the launch of a RAM approach. The RAM would be analyzed and defined at central level; on the basis of the RAM the relationship between AYS and the MMUs may be subject to some Performance Based Contract (PBC) arrangements;

D. "Linear" O\&M approach, specialized to the M network, asset management based, segmentation of the network in trunks and assignment of the O\&M to contractors, under PBC arrangements: In this option the AYS is the O\&M coordinator, it sets strategies and defines objectives and parameters (based on the RAM). Execution is contracted to external operators on the basis of PBC arrangements ("fence-to-fence" operation concept). The external operators would be responsible for keeping the road assigned to them in pristine conditions and to operate it according to the contractual clauses for a defined amount of time. The payment for the service may be based on shared estimates of the foreseeable costs, also depending on the traffic. Checkpoints may be foreseen to evaluate and repair always possible changes from the initial forecasts;

E. "Linear" O\&M approach, specialized to the $\mathrm{M}$ network, segmentation of the network in trunks and grant of the trunks to contractors under shadow tolling contractual arrangements: The general operation of given trunks of the network is contracted to external entities. The entities may be private, public or mixed, their status may evolve with the maturity of the system. Remuneration is granted on the basis of shadow tolling contracts for a certain number of years. Contracts may be issued by AYS or directly by the state, AYS would set the objectives and would be in charge of the proper application of its clauses. Payment of the service would depend on the actual traffic (e.g. number of axles) that ran along the road each year;

F. Global network approach, specialization of the M network, grant of the entire network O\&M under shadow tolling or real tolling concession arrangement: The entire network management is granted to a third entity (it may be public, of mixed ownership, or private). The contract may be issued by AYS or directly by the state. AYS would set the objectives and would be in charge of the proper application of its clauses. The remuneration of the external entity may come from a shadow tolling arrangement or it might be based on real tolls collection, cross-financing between wealthier and poorer trunks may be allowed.

\section{Comparative SWOT analysis of proposed options: analysis}

The comparative analysis has been performed by means of the SWOT (Strengths, Weaknesses, Opportunities, Threats) analysis method. Eventually considerations on the maturity of the Azeri current legislative and market development constraints lead to prioritize the first four options, because the options $E$ and $\mathrm{F}$ would have been hardly applicable in the short term; they were left in the theoretical list though, as a potential tool for the future.

The following tables summarize the analysis for each of the four options that were examined in detail regarding the possible new organization for the M network O\&M.

\section{Preferred option and proposals for its application to the main road network operation and maintenance}

As a result of the analysis the option that appears currently fit for a relatively swift application is the option $\mathrm{C}$ that includes, in summary:

(i) The completion of the set-up of the MU as a coordination entity;

(ii) The creation of a limited number of MMUs, out of the current RMUs, devoted to the M network O\&M only. The MMUs would be in charge of a relatively large length of the network (between $200 \mathrm{~km}$ and 300 $\mathrm{km}$ may be a good sizing) compared to the length operated by the existing RMUs;

(iii) The design and the initial application of a RAM system. The MU would be in charge of this task also; 
Table 1 "Do-nothing" scenario, with MU in function (option A)

\begin{tabular}{|l|l|}
\hline $\begin{array}{l}\text { Strengths } \\
\text { - simplest solution } \\
\text { - it does not change the current organization } \\
\text { - it would allow the MU to fully test the potential of the current system }\end{array}$ & $\begin{array}{l}\text { Weaknesses } \\
- \text { it does not address some of the objectives set } \\
\text { - because of inefficiencies at local level, the situation may not change much } \\
\text { - international practice proves that all the advanced nations left the area } \\
\text { based O\&M in favor of a "linear based" solution } \\
\text { - relationship between AYS and RMUs could not actually change } \\
\text { - all RMUs would need refurbishment, equipment, education, only a part of } \\
\text { which would go to the benefit of the M network }\end{array}$ \\
\hline $\begin{array}{l}\text { Opportunities } \\
\text { - let the MU the time to test and cherry-pick the best of the existing personnel } \\
\text { and equipment of the RMUs }\end{array}$ & $\begin{array}{l}\text { Threats } \\
\text { - the network could further deteriorate and the costs for the overhauling } \\
\text { would increase } \\
\text { communications over the M network would be affected adversely } \\
\text { the M network problems could hinder development in Azerbaijan }\end{array}$ \\
\hline
\end{tabular}

Table 2 "Linear" O\&M approach, limited number of MMUs (option B)

\begin{tabular}{|l|l|}
\hline $\begin{array}{l}\text { Strengths } \\
\text { - complies with the mainstream international practice } \\
\text { - creation of a "core team" of O\&M experts and professionals for the M } \\
\text { network }\end{array}$ & $\begin{array}{l}\text { Weaknesses } \\
\text { - implies the necessity to re-manage the current organization and to define } \\
\text { necessity to provide high quality equipment to a limited number of } \\
\text { structures only } \\
\text { - reduces the number of structures that the MU has to coordinate and control } \\
\text { - } \begin{array}{l}\text { brings efficiency to the system } \\
\text { it is still based on the application of the current practice and norms in terms } \\
\text { of O\&M }\end{array}\end{array}\left|\begin{array}{l}\text { Opportunities } \\
\text { - "professionalize" the M network O\&M and be of example for the entire Azeri } \\
\begin{array}{l}\text { road sector } \\
\text { - start educating professionals that may in the future be part of a more } \\
\text { market oriented system } \\
\text { - create new opportunities for employment of educated professionals }\end{array}\end{array}\right| \begin{array}{l}\text { - the current RMUs system restructuring can be difficult and can take time } \\
\text { the approach implies a profound change for those involved, some } \\
\text { resistance from the structures and from the personnel may arise } \\
\text { the transitional phase may be critical, it has to be swift so to not have } \\
\text { adverse effects on the maintenance of the M network }\end{array}$ \\
\hline
\end{tabular}

Table 3 "Linear" O\&M approach, limited number of MMUs, RAM approach (option C)

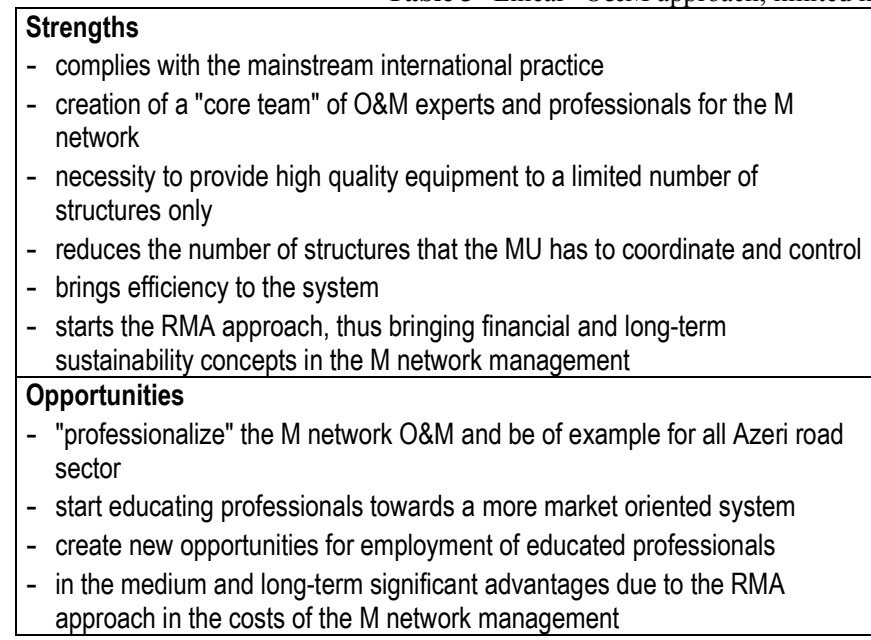

\section{Weaknesses}

- implies the necessity to re-manage the current organization and to define the new MMUs in terms of location, personnel and equipment

\section{Threats}

- the current RMUs system restructuring can be difficult and can take time

- the approach implies a profound change for those involved, some resistance from the structures and from the personnel may arise

- the transitional phase may be critical, it has to be swift so to not have adverse effects on the maintenance of the $\mathrm{M}$ network

Table 4 "Linear" O\&M approach, RMA approach, network split in trunks and assignment of the O\&M to contractors, under PBC arrangements (option D)

\begin{tabular}{l} 
Strengths \\
- complies with some mainstream international practice \\
- very advanced market approach \\
- no necessity to refurbish existing RMUs \\
- brings efficiency to the system \\
- starts the RMA approach \\
\hline Opportunities \\
- "professionalize" the M network O\&M and be of example for the entire Azeri \\
road sector \\
- new market sector opening \\
- create new opportunities for employment of educated professionals \\
- in the medium and long-term the costs of the M network management can \\
have significant advantages due to the RMA approach
\end{tabular}

(iv) The definition of performance based contractual schemes to be used in the relation between the MU and the MMUs and to serve as the basis for future

\section{Weaknesses}

- implies the necessity to create a framework for the PPP

- the monitoring framework to assess the contractors' efficiency may take some time to be developed and tested

- market may not be ready in Azerbaijan for this solution

\section{Threats}

- the contractors market might not be mature enough for this choice, in the case the deployment of the solution may be badly delayed

- to set up and to test the monitoring/control tools may lead to temporary bad performances in the early phases of implementation

contracts in case of evolution of the MMUs towards more market oriented schemes or in the event of an 
outsourcing of O\&M (entire or partial) to the private sector.

This option resulted as the more preferable among all the others because it matches the basic principles and the basic objectives of the action, and it can be implemented also without major legislative changes and without relying excessively on the private sector that, at the moment, does not show yet the level of maturity in O\&M needed for the operation of an important national network [6].

The implementation of the option $\mathrm{C}$ will as a matter of fact allow the Azeri public sector to develop expertise on the RAM and on the PBC approach, will lead to the restructuring of the $\mathrm{M}$ network O\&M assignment and to the specialization, and to better professionalization by means of the MMUs creation. Professionals will be able to grow specific expertise within the MMUs that could in the initial phases of this new arrangement fine tune the relationship with the AYS, in the perspective of an opening to the market. The MMUs may also have a certain degree of freedom in procuring activities and works along the trunks falling within their jurisdiction.

One of the main advantages of the option $\mathrm{C}$ lies in the fact that, although the most of the O\&M assignments are left to the public sector, this option does not prevent any future choice based on the other, more market oriented, options. Indeed, the implementation of the option " $\mathrm{C}$ " would permit the AYS to acquire the experience and the know-how in the field of PBCs in a controlled environment then, when the system will have become stable, its evolution towards the other more market oriented options can be envisaged.

The application of the option $\mathrm{C}$ is perfectly in line with the activities done so far concerning the realization of the MU, of which it would constitute a natural evolution. In practical terms the implementation of the option " $C$ " requires some steps that can be summarized as follows:

(a) Completion of the MU set up. The MU will have to become completely operational and will have to start developing the asset management schemes that will have to guide the future operation;

(b) Definition of the apportionment of the $\mathrm{M}$ network among the newly created MMUs. It is important to define the MMUs and their assignments in a balanced way and in the perspective of a sustainable operation. Trunks assigned to single MMUs should have an internal consistence in terms of needs, traffic and conditions, so to optimize MMUs personnel and equipment provision and skills/capacities.

(c) In practical terms, a first proposal may see the stepwise creation of $6 \mathrm{MMUs}$, in charge of lengths of network ranging from $210 \mathrm{~km}$ to $315 \mathrm{~km}$ thus covering the whole $\mathrm{M}$ network in a pretty balanced way. The MMUs competences repartition is sketched in Fig. 2;

(d) Organization of the single MMUs, that will have to be equipped for all the expected O\&M needs along their specific trunk, ordinary maintenance of winter operation as well as some works, and will have to be capable to monitor the relevant data of interest for the AMS. MMUs should have a certain degree of independence, within the prescribed SLAs and within their performance based arrangements, and have some procurement capacity to contract specialist service, hire equipment, or outsource some of the activities. Their O\&M capability should be understood in a broad meaning, including also the ability to deal with road signalization and traffic and to be swiftly of support in the event of incidents or of other occurrences that may limit the road availability or deteriorate its conditions;

(e) Organization of educational schemes for the MMUs personnel, having in mind the concept of continuous learning, since road management is an evolving discipline and the evolution in Azerbaijan, also in terms of operational needs, will be presumably faster than in other countries.

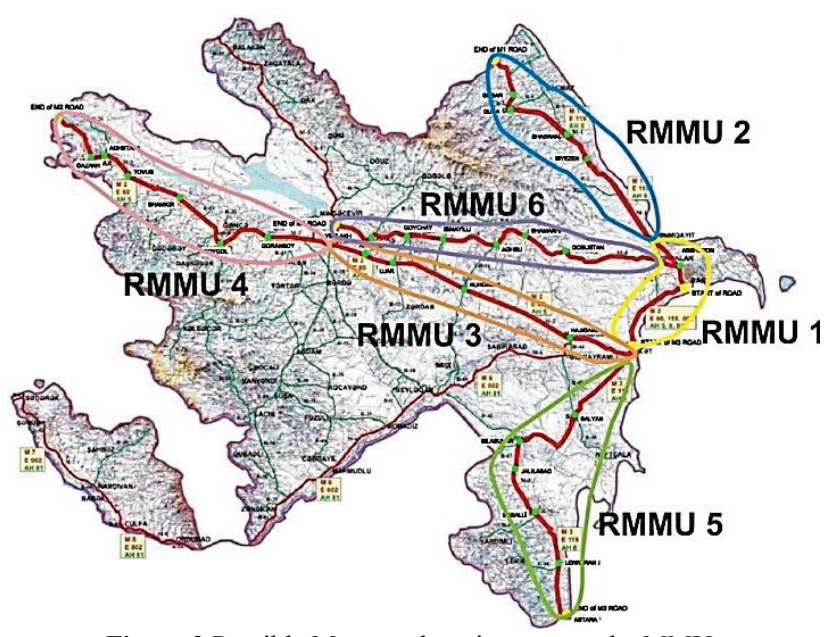

Figure 2 Possible $M$ network assignment to the MMUs

\section{Conclusion}

As opposed to the current practice in Azerbaijan, primary national networks in developed nations do have such a level of importance and of specific needs that their management (including O\&M) asks for special and high level capabilities and knowledge. The common practice is the one of "linear management" of primary roads, as opposed to "area management" that may find application on lower level road networks (secondary and local roads). Therefore the management (and the maintenance) is not merged with the one of lower level networks, and may include an increasing number of traffic management tasks well beyond the simple construction and repair of the road.

The role of a primary road network manager asks for capability and knowledge in a broad range of subjects and of activities, currently not dealt with along the Azeri primary network. It is advisable to determine a sustainable stepwise approach of implementation, from short-term to long-term objectives.

In summary, there is a significant gap between the international consolidated practice in primary road networks O\&M and the current Azeri practice; examples are available for overall organization, for contracting practices, for technical means and methods. There is ample room for evolution in the primary network O\&M practice and the international historical experience tells that a comprehensive approach in framing all the 
components of the O\&M also in a long-term perspective can be beneficial for planning purposes.

The analysis of possible options for a transformation phase highlights that at the current moment the most urgent actions, further to the already launched creation of the MU within AYS, are the setup of a RAM approach, that can guide the future steps of the O\&M evolution along the Azeri motorways, and replacement of the current maintenance scheme, based on small RMUs serving all the roads in an area, with a more advanced scheme with few MMU, specialized in motorways O\&M and coordinated by the AYS MU by means of SLA based arrangements.

Future evolutions may see larger opening to the market, with private operators that might deliver the service on the basis, for instance of $\mathrm{PBC}$, or even the introduction of tolling concession based contractual arrangements.

\section{Acknowledgements}

The research presented in this paper was conducted with the support of the AzerYolServis ASC, through the Azerbaijan Highway Project III, and presents a part of the research made during Technical Assistance for Establishment of a Motorway Management Unit and Modernization of Motorway Management Practices in Azerbaijan. The authors extend their thanks to all authorities that approved the use of the data for their kind assistance and understanding.

\section{References}

[1] Asset Management for Roads-An Overview. World Road Association, Paris, 2005

[2] Asset Management Practice. World Road Association, Paris, 2008.

[3] The Move of the European Road Administrations toward Network Operations. Conference of European Directors of Roads, Brussels, 2004.

[4] Road Network Operations Handbook. World Road Association, Paris, 2003

[5] Azerbaijan Road Sector Master Plan, Final Report. Destia Finnroad, AzerYolServis, Baku, 2012.

[6] Report on Capacity of Public and Private Sector Operators. Azerbaijan Highway Project III, IRD Engineering/ISO 2000/SPT, AzerYolServis, Baku, 2013.

[7] Improving the Sustainability of Road Management and Financing in Azerbaijan. World Bank, Washington, D.C. 2011.

[8] Archutowska, J.; Pieriegud, J. Effectiveness of National Roads Maintenance Management in Poland. Ernst \& Young, Warsaw, 2012.

[9] Report on Optional Strategies for Motorway Operation and Maintenance. Azerbaijan Highway Project III, IRD Engineering/ISO 2000/SPT, AzerYolServis, Baku, 2013.
Authors' addresses

Igor Jokanović, Ph.D. Civil Eng., Assistant professor University of Novi Sad,

Faculty of Civil Engineering,

Kozaračka 2a, 24000 Subotica, Serbia

E-mail: jokanovici@gf.uns.ac.rs

Maurizio Rotondo, Dr. in Civil Engineering, Consultant Piazza Marconi 15, 00144 Rome, Italy

E-mail:mrotondo@e-rotondo.eu

Dragan Mihajlović, Ph.D. Civil Eng.

IG inženjering Ltd.

Ruska bb, 89000 Trebinje, Bosnia and Herzegovina E-mail:dram@inecco.net 